\title{
Combining perfusion and angiography with a low-dose cardiac CT technique: a preliminary investigation in a swine model
}

\author{
Logan Hubbard ${ }^{1}\left([) \cdot\right.$ Shant Malkasian $^{1} \cdot$ Yixiao Zhao $^{1} \cdot$ Pablo Abbona $^{1} \cdot$ Sabee Molloi ${ }^{1}(\mathbb{0}$
}

Received: 18 October 2020 / Accepted: 4 December 2020 / Published online: 27 January 2021

(c) The Author(s) 2021

\begin{abstract}
Morphological and physiological assessment of coronary artery disease (CAD) is necessary for proper stratification of CAD risk. The objective was to evaluate a low-dose cardiac CT technique that combines morphological and physiological assessment of CAD. The low-dose technique was evaluated in twelve swine, where three of the twelve had coronary balloon stenosis. The technique consisted of rest perfusion measurement combined with angiography followed by stress perfusion measurement, where the ratio of stress to rest was used to derive coronary flow reserve (CFR). The technique only required two volume scans for perfusion measurement in $\mathrm{mL} / \mathrm{min} / \mathrm{g}$; hence, four volume scans were acquired in total; two for rest with angiography and two for stress. All rest, stress, and CFR measurements were compared to a previously validated reference technique that employed 20 consecutive volume scans for rest perfusion measurement combined with angiography, and stress perfusion measurement, respectively. The $32 \mathrm{~cm}$ diameter volumetric $\mathrm{CT}$ dose index $\left(\mathrm{CTDI}_{\mathrm{vol}}^{32}\right)$ and size-specific dose estimate (SSDE) of the low-dose technique were also recorded. All low-dose perfusion measurements $\left(\mathrm{P}_{\mathrm{LOw}}\right) \mathrm{in} \mathrm{mL} /$ $\mathrm{min} / \mathrm{g}$ were related to reference perfusion measurements $\left(\mathrm{P}_{\mathrm{REF}}\right)$ through regression by $\mathrm{P}_{\mathrm{LOW}}=1.04 \mathrm{P}_{\mathrm{REF}}-0.08(\mathrm{r}=0.94$, $\mathrm{RMSE}=0.32 \mathrm{~mL} / \mathrm{min} / \mathrm{g}$ ). The $\mathrm{CTDI}_{\mathrm{vol}}^{32}$ and SSDE of the low-dose cardiac CT technique were $8.05 \mathrm{mGy}$ and $12.80 \mathrm{mGy}$ respectively, corresponding to an estimated effective dose and size-specific effective dose of 1.8 and $2.87 \mathrm{mSv}$, respectively. Combined morphological and physiological assessment of coronary artery disease is feasible using a low-dose cardiac CT technique.
\end{abstract}

Keywords Coronary artery disease $\cdot$ Computed tomography angiography $\cdot$ Myocardial perfusion imaging $\cdot$ Coronary flow reserve

$\begin{array}{ll}\text { Abbreviations } \\ \text { CAD } & \text { Coronary artery disease } \\ \text { CCC } & \text { Lin's concordance correlation coefficient } \\ \text { CFR } & \text { Coronary flow reserve } \\ \text { CT } & \text { Computed tomography } \\ \text { CTDI }_{\text {vol }}{ }^{32} & \text { 32 Cm diameter volumetric CT dose index } \\ \text { FFR } & \text { Fractional flow reserve } \\ \text { HU } & \text { Hounsfield Unit } \\ \text { SSDE } & \text { Size-specific dose estimate } \\ \text { V1 } & \text { Volume scan } 1 \\ \text { V2 } & \text { Volume scan } 2\end{array}$

Sabee Molloi

symolloi@uci.edu

1 Department of Radiological Sciences, Medical Sciences I, B-140, University of California, Irvine, CA 92697, USA

\section{Introduction}

Computed tomography angiography (CTA) is a powerful tool for coronary artery disease (CAD) risk stratification. Nevertheless, CTA only assesses the morphological severity of segmental CAD and cannot define the physiological severity of concurrent multi-vessel, diffuse, and microvascular disease, or myocardial scar. Hence, additional physiological assessment with single-photon emission computed tomography, stress echocardiography, cardiac magnetic resonance, static positron emission tomography (PET), or static $\mathrm{CT}$ is recommended for better stratification of patient risk. However, such modalities only provide metrics of relative perfusion or scar extent; hence, they cannot determine the true severity of CAD [1-8].

Fortunately, the spatial distribution of absolute stress perfusion in $\mathrm{mL} / \mathrm{min} / \mathrm{g}$ and coronary flow reserve (CFR), defined as the ratio of stress to rest perfusion, can be used to overcome these limitations by enabling localization and 
delineation of focal, diffuse, and microvascular disease, as well as scar [3, 9]. While such measurements are possible with dynamic PET [3] and quantitative MRI [10], access and cost greatly limit their routine application. That said, such measurements are also possible with dynamic CT. Nevertheless, despite positive correlation with microsphere perfusion, current dynamic CT perfusion techniques underestimate perfusion secondary to inadequate compartment modelling and temporal sampling limitations [11-13]. Moreover, they deliver a high effective radiation dose per exam $(\sim 5 \mathrm{mSv}$ or greater) [5, 14-16], which further compounds when separate CTA is also performed $[2,16]$

There is a major unmet clinical need for an accurate, lowdose CT technique capable of combined morphological and physiological assessment of CAD. Enabled by wide-detector $\mathrm{CT}$, our prior research has sought to provide a solution. First, we developed a new dynamic CT perfusion technique, validating that global perfusion measurement was feasible in an idealized phantom model of the heart using only two volume scans, with an ultrasonic flow probe as the reference standard [17]. Next, we retrospectively developed this technique in a swine model of ischemic coronary artery disease, validating vessel-specific [18] perfusion measurement as compared with invasive fractional flow reserve (FFR) and quantitative microsphere perfusion measurement, respectively [19, 20]. Finally, we determined that accurate retrospective and prospective assessment of global stress perfusion is feasible at a tube current as low as $50 \mathrm{~mA}$ [21]. Nevertheless, despite these data, accurate, vessel-specific stress perfusion, CFR, and CTA measurement remained to be combined and validated as a true low-dose cardiac CT technique. Hence, the purpose of this study was to assess the accuracy of a new low-dose cardiac CT technique, using our previously validated retrospective technique as the reference standard for perfusion measurement [18-21]. The central hypothesis was that accurate, low-dose, vessel-specific rest perfusion, stress perfusion, and CFR measurement is feasible, with simultaneously acquired co-registered CTA data, using a total of only four volume scans and two contrast injections.

\section{Materials and methods}

\section{Low-dose cardiac CT technique}

First-pass analysis and conservation of mass state that the average perfusion $\left(\mathrm{P}_{\mathrm{AVE}}\right)$ within the entire myocardium, modelled as a single compartment, is proportional to the rate of contrast mass entry over the measurement time $\left(\mathrm{dM}_{\mathrm{C}} / \mathrm{dt}\right.$, in grams of Iodine per minute), normalized by the average blood pool contrast concentration $\left(\mathrm{C}_{\mathrm{in}}\right.$, in grams of Iodine per milliliter of blood) and total myocardial tissue mass $\left(\mathrm{M}_{\mathrm{T}}\right.$, in grams), assuming measurements are made prior to contrast outflow. Of importance, $\mathrm{dM}_{\mathrm{C}} / \mathrm{dt}$ and $\mathrm{C}_{\mathrm{in}}$ are not directly measured but are instead linearly related to the tissue and blood enhancement in Hounsfield Units (HU) by the same constant. As this constant cancels in ratio in Eq. 1, all calculations can be performed using the tissue and blood HU alone. Note also that the myocardium volume is fixed, i.e., measurements are derived using the same cardiac phase. Hence, $\mathrm{P}_{\mathrm{AVE}}$ is also proportional to the average change in contrast concentration, represented by the change in enhancement, $\Delta \mathrm{HU}_{\mathrm{AVE}}$, in the entire myocardium over the measurement time. Given this derivation, only two wholeheart volume scans, V1 and V2 shown in Fig. 1a, are necessary for perfusion measurement, as previously validated retrospectively versus invasive FFR, quantitative microsphere perfusion, and ultrasonic flow probe measurement [17, 19, 20]. V1 occurs after the aortic enhancement exceeds 140 HU above the baseline blood pool enhancement, while V2 occurs at approximately the peak of the aortic enhancement, i.e., it may also be used as a CTA if acquired at a diagnostic tube current $[19,20] . \mathrm{dM}_{\mathrm{C}} / \mathrm{dt}$ is calculated by summating all voxel values (in $\mathrm{HU}$ ) within the myocardium of both the $\mathrm{V} 1$ and V2 volume scans, determining their difference, then dividing by time (where $\mathrm{dt}$ is calculated from the $\mathrm{V} 1$ and $\mathrm{V} 2$ acquisition times). Similarly, $\Delta \mathrm{HU}_{\mathrm{AVE}}$ is calculated by averaging all voxel values (in $\mathrm{HU}$ ) within the myocardium of both the V1 and V2 volume scans and determining their difference. $C_{\text {in }}$ is defined as the central enhancement of blood pool in the aortic root in $\mathrm{HU}$ averaged between $\mathrm{V} 1$ and $\mathrm{V} 2$. Finally, $\mathrm{M}_{\mathrm{T}}$ is defined as the density of myocardial tissue (1.055 g per milliliter [22]) multiplied by the total myocardial volume. In combination with the voxel-by-voxel differences in myocardial enhancement in $\mathrm{HU}$ between $\mathrm{V} 1$ and V2 ( $\Delta \mathrm{HU}$, determined simply through image subtraction), the perfusion $(\mathrm{P})$ in each voxel in $\mathrm{mL} / \mathrm{min} / \mathrm{g}$ can be derived, as described by Eq. 1 .

$P=\left(M_{T}^{-1} C_{i n}^{-1} \frac{d M_{c}}{d t}\right)_{A V E} \cdot \frac{\Delta H U}{\Delta H U_{A V E}}$

\section{General study design}

The study, approved by the Institutional Animal Care and Use Committee at the University of California Irvine, was performed on twelve male Yorkshire swine $(41 \pm 11 \mathrm{~kg})$ between February and December of 2017. Of the twelve animals, three had sub-occlusive balloon stenosis in the left anterior descending (LAD) coronary artery. Of additional note, the stress data from eight of the twelve animals (including the three with stenosis) were used in a prior study [21]. Each animal was prospectively imaged with the low-dose cardiac CT technique. The CT protocol consisted of rest perfusion measurement combined with angiography followed 


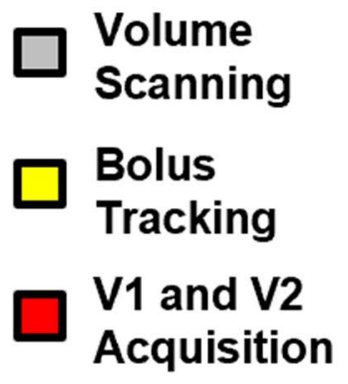

(a)

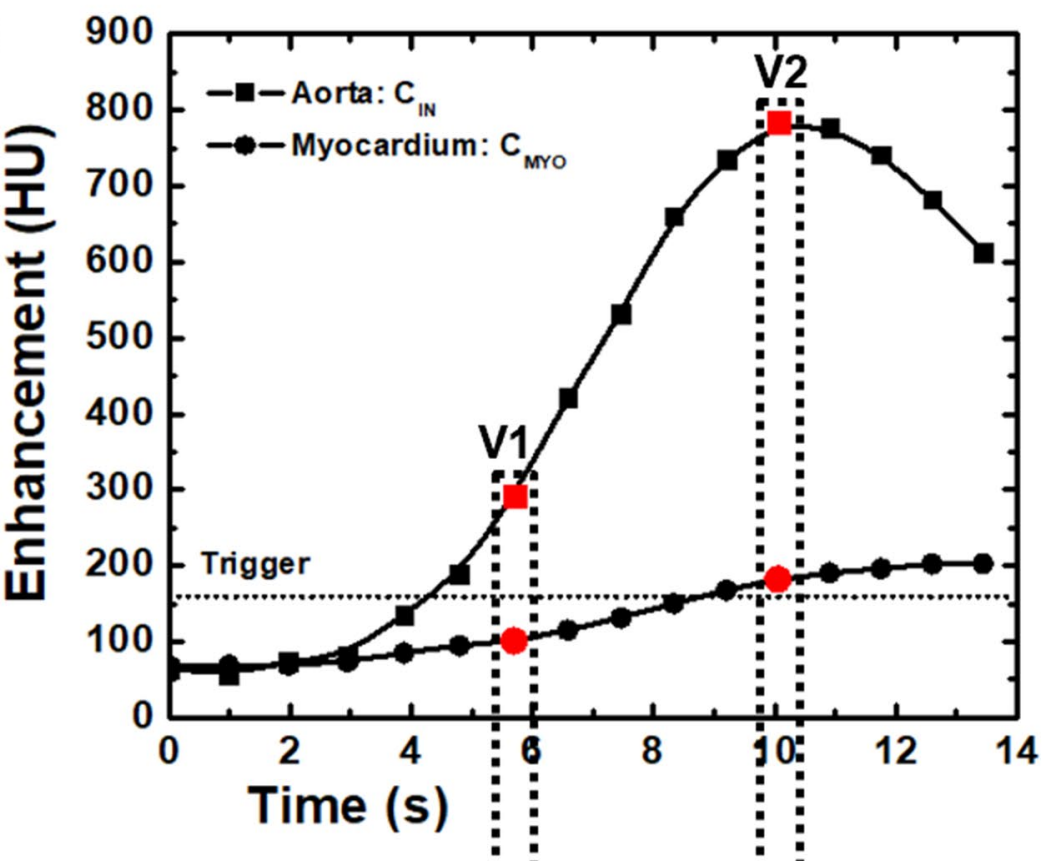

(b)

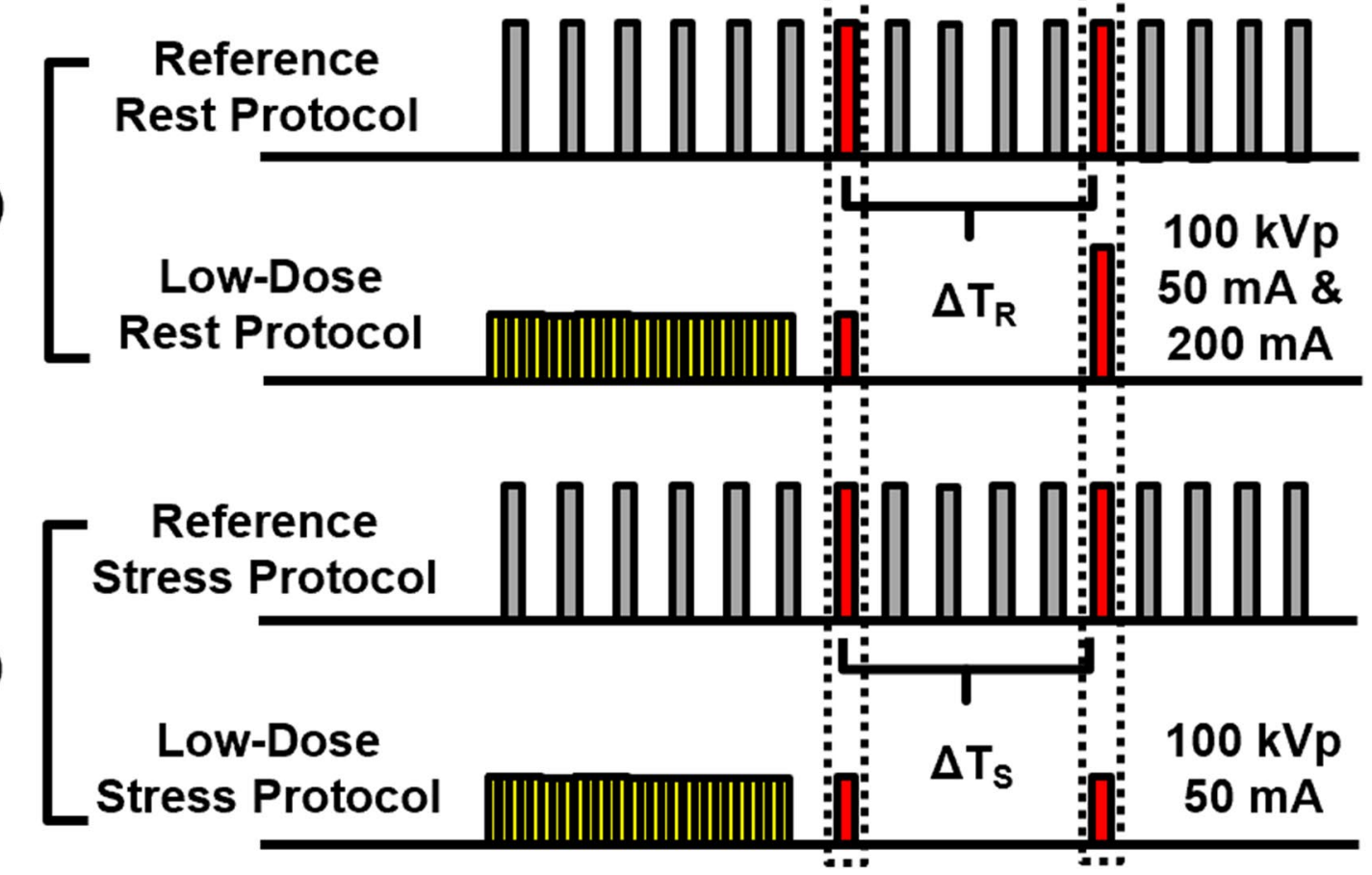

Fig. 1 Low-dose cardiac CT technique. a The first-pass enhancement within the aorta and myocardium are shown, where V1 and V2, shown in red, are used for CT perfusion (CTP) measurement, while V2 is also used for CTA during rest conditions. b The reference standard rest perfusion and CTA protocol is comprised of consecutive acquisition of 20 volume scans at $100 \mathrm{kVp}$ and $200 \mathrm{~mA}$. The low-dose rest perfusion and CTA protocol is comprised of 2-mm slab dynamic bolus tracking at $100 \mathrm{kVp}$ and $50 \mathrm{~mA}$, threshold-based trig-

by stress perfusion measurement, where the ratio of stress to rest was used to derive CFR. Only four volume scans were gering, then acquisition of $\mathrm{V} 1$ and $\mathrm{V} 2 . \mathrm{V} 1$ is acquired at $100 \mathrm{kVp}$ and $50 \mathrm{~mA}$, while V2 is acquired at $100 \mathrm{kVp}$ and $200 \mathrm{~mA}$ and is used for additional CTA. $\mathbf{c}$ The reference standard stress perfusion protocol is comprised of consecutive acquisition of 20 volume scans at $100 \mathrm{kVp}$ and $200 \mathrm{~mA}$. The low-dose stress perfusion protocol is comprised of 2-mm slab dynamic bolus tracking at $100 \mathrm{kVp}$ and $50 \mathrm{~mA}$, thresholdbased triggering, then acquisition of V1 and V2. Both V1 and V2 are acquired at $100 \mathrm{kVp}$ and $50 \mathrm{~mA}$

acquired in total by the protocol: two for rest with angiography and two for stress. All low-dose rest, stress, and 
CFR measurements were then compared to corresponding measurements with a reference standard retrospective technique $[17,19,20]$, where the reference technique also only required two retrospectively selected volume scans for perfusion measurement, as previously validated versus invasive FFR, quantitative microsphere perfusion, and ultrasonic flow probe measurement $[17,19,20]$.

\section{Animal preparation}

Anesthesia was induced with Telazol (4.4 mg/kg), Ketamine $(2.2 \mathrm{mg} / \mathrm{kg})$, and Xylazine $(2.2 \mathrm{mg} / \mathrm{kg})$, and was maintained with 1.5-2.5\% Isoflurane (Highland Medical Equipment, Temecula, CA and Baxter, Deerfield, IL). Sheaths were placed (AVANTI®, Cordis Corporation, Miami Lakes, FL) in both femoral veins for intravenous adenosine and contrast administration. In three of the animals, an extra sheath was placed in the right carotid artery to pass a Judkins Right (JR) catheter (Cordis Corporation, Miami Lakes, FL) into the left coronary ostium. A pressure wire (PrimeWire PRESTIGE® Pressure Guide Wire, Volcano Corp, Rancho Cordova, CA) was then advanced into the distal LAD. A balloon was passed over the wire into the mid LAD and was used to generate several levels of sub-occlusive stenosis with FFR (ComboMap, Volcano Corp., Rancho Cordova, CA) severities of $0.7-0.9$ under maximal vasodilation (240 $\mu$ g adenosine/kg/min, Model 55-2222, Harvard Apparatus, Holliston, MA). Beta blockers were not administered for heart rate control and nitroglycerin was not administered during CTA.

\section{Reference standard rest perfusion, CTA, and stress perfusion protocol}

For rest perfusion conditions, contrast ( $1 \mathrm{~mL} / \mathrm{kg}$, Isovue 370 , Bracco Diagnostics, Princeton, NJ) was injected $(5 \mathrm{~mL} / \mathrm{s}$, Empower CTA, Acist Medical Systems, Eden Prairie, $\mathrm{MN})$ followed by a saline chaser $(0.5 \mathrm{~mL} / \mathrm{kg})$ at the same rate. Twenty consecutive whole-heart volume scans were then acquired during diastole using prospective ECGgating. All scanning was performed in CINE mode at 100 $\mathrm{kVp}$ and $200 \mathrm{~mA}$, and all volumes were acquired as full projections(Aquilion One, Canon Medical Systems, Tustin, CA). For stress perfusion conditions, maximum vasodilation was induced for two minutes prior to imaging, and was maintained during acquisition, where contrast injection and volume scan acquisition remained the same as above. All volume scans had a 0.35 s rotation time and $320 \times 0.5 \mathrm{~mm}$ collimation for a total of $16 \mathrm{~cm}$ of $\mathrm{z}$-axis coverage. The $32 \mathrm{~cm}$ diameter volumetric CT dose index $\left(C T D I_{\text {vol }}^{32}\right)$ was recorded and a size-specific dose estimate (SSDE) was determined [23] to account for the differing chest diameters of each swine. After each acquisition, V1 and V2 were selected systematically for reference standard rest or stress perfusion measurement, as previously validated versus invasive FFR, quantitative microsphere perfusion, and ultrasonic flow probe measurement [17, 19, 20], while the rest V2 acquisition was also used for CTA [19, 20]. Finally, the variable time delay $(\Delta \mathrm{T})$ between $\mathrm{V} 1$ and $\mathrm{V} 2$ was estimated from each aortic time-density-curve and was used for each subsequent low-dose rest perfusion and CTA acquisition, as well as for each low-dose stress perfusion acquisition. Both reference standard protocols are shown in Fig. $1 \mathrm{~b}$ and c.

\section{Low-dose rest perfusion and CTA protocol}

Following each reference standard rest acquisition, a 15-min delay was employed to allow for adequate recirculation and redistribution of contrast within the blood pool and interstitium. Contrast and saline were then injected, as described in Sect. 2.4. Dynamic bolus tracking at $100 \mathrm{kVp}$ and $50 \mathrm{~mA}$ (SureStart, Aquilion One, Canon Medical Systems, Tustin, CA) was then used, with V1 acquired after the aortic enhancement exceeded $140 \mathrm{HU}$ above the baseline blood pool enhancement and V2 acquired after V1 using the previously estimated time delay, $\Delta \mathrm{T}$. V1 was acquired at $100 \mathrm{kVp}$ and $50 \mathrm{~mA}$ while $\mathrm{V} 2$ was acquired at $100 \mathrm{kVp}$ and $200 \mathrm{~mA}$ and was also used for CTA. The $C T D I_{v o l}^{32}$ and SSDE of the protocol and its individual components were also determined [23]. The entire protocol is shown in Fig. 1b.

\section{Low-dose stress perfusion protocol}

Following each reference standard stress acquisition, a 15-min delay was again employed. Maximal vasodilation was then induced, as described in Sect. 2.4, and was maintained during acquisition. Contrast and saline were then injected, and dynamic bolus tracking at $100 \mathrm{kVp}$ and $50 \mathrm{~mA}$ was used, as described in Sect. 2.4, where V1 and $\mathrm{V} 2$ were both acquired at $100 \mathrm{kVp}$ and $50 \mathrm{~mA}$. The $C T D I_{v o l}^{32}$ and SSDE of the protocol were also determined [23]. The entire protocol is shown in Fig. 1c.

\section{Low-dose and reference standard cardiac CT image processing}

For each acquisition, all volume scans were first reconstructed from full projection data at $75 \%$ of the R-R interval using AIDR 3D reconstruction [24] (Canon Medical Systems, Tustin, CA) and a voxel size of $0.43 \times 0.43 \times 0.5 \mathrm{~mm}$. Next, the volume scans of interest-V $1_{\text {REST }}, \mathrm{V} 2_{\text {REST }}, \mathrm{V} 1_{\text {STRESS }}$, and $\mathrm{V} 2_{\text {STRESS }}$-were automatically registered [25] and combined into a maximum intensity projection (MIP) image volume. Vitrea was then used for accurate semi-automatic segmentation of the myocardium(Vitrea $\mathrm{fX}$ version 6.0, Vital Images, Inc., Minnetonka, MN) [26, 27], yielding the myocardial tissue compartment, after which custom in-house software was used 
for perfusion and CFR calculation. Specifically, the average compartmental rest and stress perfusion $\left(\mathrm{P}_{\mathrm{AVE}}\right)$ were calculated as the integrated change in $\mathrm{HU}$ within the compartment between corresponding volume scans $\left(\mathrm{dM}_{\mathrm{C}} / \mathrm{dt}\right)$ normalized by the blood pool contrast concentration $\left(\mathrm{C}_{\mathrm{in}}\right.$, calculated from the average aortic HU between V1 and V2) and myocardial tissue mass $\left(\mathrm{M}_{\mathrm{T}}\right.$, calculated as the product of the compartment volume and tissue density). The average compartmental perfusion was then combined with the average and per-voxel changes in $\mathrm{HU}\left(\Delta \mathrm{HU}_{\mathrm{AVE}}\right.$ and $\left.\Delta \mathrm{HU}\right)$ between volume scans to yield voxel-by-voxel rest perfusion, stress perfusion, and CFR measurements. Finally, Vitrea was used for accurate semi-automatic extraction of the LAD, LCx, and RCA centerlines from the $\mathrm{V} 2_{\mathrm{REST}} \mathrm{CTA}$ volume scan (Vitrea fX version 6.0, Vital Images, Inc., Minnetonka, MN) [26, 27], and minimum-cost-path myocardial assignment was performed, yielding three separate coronary perfusion territories, with the LAD territory further partitioned distal to each stenoses, as previously reported $[18-20,28]$. The average rest perfusion, stress perfusion, and CFR within each territory was then calculated, and quantitative comparisons were made between the low-dose and reference standard retrospective measurements.

\section{Statistical approach}

Using Shapiro-Wilk testing, all rest and stress perfusion measurements were first verified to be normally distributed. The measurement variance within each animal was then assessed as compared to the measurement variance between each animal, resulting in an intra-cluster correlation of 0.49 , indicating minimal correlation between intra-animal measurements; hence, all measurements were assumed to be independent for the remainder of analyses. Low-dose perfusion measurements in the LAD, LCx, and RCA were quantitatively compared to corresponding reference standard perfusion measurements through regression, Bland-Altman, root-mean-square-error (RMSE: accuracy as compared to the reference standard), root-mean-square deviation (RMSD: precision as compared to the regression fit), and Lin's concordance correlation coefficient (CCC). Student's T-tests were also performed to compare low-dose perfusion and CFR measurements to corresponding reference standard perfusion and CFR measurements. All data are reported with $95 \%$ confidence intervals. All other data are reported as mean \pm standard deviation. P-values less than 0.05 indicate significant differences. Statistical software was used for analyses (PS, Version 3.0, Vanderbilt University, Nashville, TN; SPSS, Version 22, IBM Corporation, Armonk, NY).

\section{Results}

\section{General}

The average rest and stress heart rates of the swine were $83 \pm 8$ and $99 \pm 7$ beats per minute, respectively, while the average rest and stress mean arterial pressures of the swine were $72 \pm 10 \mathrm{mmHg}$ and $66 \pm 10 \mathrm{mmHg}$, respectively. The time delay between $\mathrm{V} 1$ and $\mathrm{V} 2$ acquisition ranged from 4.10 to $8.93 \mathrm{~s}$ with an average of $5.69 \pm 1.35 \mathrm{~s}$. The average data processing time per swine for all acquisitions combined was approximately one hour, with most of the time spent on semi-automatic segmentation of the myocardium and coronary centerlines. The average lowdose rest and stress perfusion in all three coronary arteries combined was $0.50 \pm 0.22$ and $1.93 \pm 0.84 \mathrm{~mL} / \mathrm{min} / \mathrm{g}$, respectively, while corresponding reference standard rest and stress perfusion was $0.58 \pm 0.21$ and $1.92 \pm 0.73 \mathrm{~mL} /$ $\mathrm{min} / \mathrm{g}$, respectively. The average CFR in all three coronary arteries combined was $3.07 \pm 1.66$, while corresponding reference standard CFR was $3.37 \pm 1.67$. The average lowdose stress perfusion in the LAD with and without stenosis was $1.20 \pm 0.32$ and $2.07 \pm 0.83 \mathrm{~mL} / \mathrm{min} / \mathrm{g}$, respectively, while corresponding reference standard stress perfusion was $1.40 \pm 0.40$ and $2.04 \pm 0.73 \mathrm{~mL} / \mathrm{min} / \mathrm{g}$, respectively. The average CFR in the LAD with and without stenosis was $1.80 \pm 0.81$ and $3.11 \pm 1.17$, respectively, while corresponding reference standard CFR was $2.19 \pm 0.69$ and $3.46 \pm 0.85$, respectively. All other low-dose perfusion and CFR measurements in the LAD, LCx, and RCA individually as compared to corresponding reference standard perfusion and CFR measurements are shown in Table 1.

\section{Accuracy and precision}

The low-dose perfusion $\left(\mathrm{P}_{\text {LOW }}\right)$ and reference standard perfusion $\left(\mathrm{P}_{\mathrm{REF}}\right)$ measurements in all three coronary arteries combined under rest and stress perfusion conditions were related through regression by $\mathrm{P}_{\mathrm{LOW}}=1.04 \mathrm{P}_{\mathrm{REF}}-0.08$, with a Pearson's correlation of $r=0.94$, a concordance correlation of $\rho=0.94$, a RMSE of $0.32 \mathrm{~mL} / \mathrm{min} / \mathrm{g}$, and a RMSD of $0.32 \mathrm{~mL} / \mathrm{min} / \mathrm{g}$, as shown in Fig. 2a and Table 2, with corresponding Bland-Altman analysis shown in Fig. 2b. Perfusion measurements under stress perfusion conditions alone were related by $\mathrm{P}_{\mathrm{LOW}}=1.04 \mathrm{P}_{\mathrm{REF}}-0.07$, with a Pearson's correlation of $r=0.90$, a concordance correlation of $\rho=0.89$, a root-mean-square-error of $0.36 \mathrm{~mL} / \mathrm{min} / \mathrm{g}$, and a root-mean-square deviation of $0.36 \mathrm{~mL} / \mathrm{min} / \mathrm{g}$, as shown in Fig. 2c and Table 2, with corresponding Bland-Altman analysis shown in Fig. 2d. Finally, perfusion measurements under rest perfusion conditions alone were related 
Table 1 Low-dose perfusion and CFR measurement and reference standard perfusion and CFR measurement mean comparison

\begin{tabular}{llll}
\hline Condition & $\begin{array}{l}\text { Low-dose measure- } \\
\text { ments }\end{array}$ & $\begin{array}{l}\text { Reference measure- } \\
\text { ments }\end{array}$ & $\begin{array}{l}\text { P-value } \\
(\alpha<0.05)\end{array}$ \\
\hline $\boldsymbol{R E S T}$ & $(\boldsymbol{m L} / \boldsymbol{m i n} / \boldsymbol{g})$ & $(\boldsymbol{m L} / \boldsymbol{m i n} / \boldsymbol{g})$ & \\
LAD & $0.58 \pm 0.18$ & $0.64 \pm 0.20$ & 0.37 \\
LCx & $0.53 \pm 0.23$ & $0.62 \pm 0.17$ & 0.23 \\
RCA & $0.37 \pm 0.24$ & $0.46 \pm 0.23$ & 0.32 \\
ALL & $0.50 \pm 0.22$ & $0.58 \pm 0.21$ & 0.06 \\
STRESS & $(\boldsymbol{m L} / \boldsymbol{m i n} / \boldsymbol{g})$ & $(\boldsymbol{m L} / \boldsymbol{m i n} / \boldsymbol{g})$ & \\
LAD & $1.88 \pm 0.83$ & $1.90 \pm 0.72$ & 0.76 \\
Normal & $2.07 \pm 0.83$ & $2.04 \pm 0.73$ & 0.64 \\
Stenosis & $1.20 \pm 0.32$ & $1.40 \pm 0.40$ & 0.12 \\
LCx & $2.15 \pm 0.96$ & $2.14 \pm 0.90$ & 0.92 \\
RCA & $1.79 \pm 0.74$ & $1.76 \pm 0.54$ & 0.73 \\
ALL & $1.93 \pm 0.84$ & $1.92 \pm 0.73$ & 0.92 \\
$\boldsymbol{C F R}$ & $(\boldsymbol{S T R E S S / R E S T )}$ & $(\boldsymbol{S T R E S S} / \boldsymbol{R} \boldsymbol{E S T})$ & \\
LAD & $2.60 \pm 1.22$ & $2.97 \pm 0.99$ & 0.06 \\
Normal & $3.11 \pm 1.17$ & $3.46 \pm 0.84$ & 0.25 \\
Stenosis & $1.80 \pm 0.81$ & $2.19 \pm 0.69$ & 0.09 \\
LCx & $3.33 \pm 0.67$ & $3.34 \pm 1.58$ & 0.97 \\
RCA & $3.65 \pm 2.73$ & $4.13 \pm 2.47$ & 0.44 \\
ALL & $3.07 \pm 1.66$ & $3.37 \pm 1.67$ & 0.15 \\
\hline P & & &
\end{tabular}

P-values less than 0.05 indicate significant mean perfusion differences

$C F R$ coronary flow reserve, $L A D$ left anterior descending perfusion territory, $L C x$ left circumflex perfusion territory, $R C A$ right coronary artery perfusion territory, $A L L$ all coronary perfusion territories combined

by $\mathrm{P}_{\mathrm{LOW}}=0.60 \mathrm{P}_{\mathrm{REF}}-0.16$, with a Pearson's correlation of $r=0.56$, a concordance correlation of $\rho=0.53$, a root-meansquare-error of $0.21 \mathrm{~mL} / \mathrm{min} / \mathrm{g}$, and a root-mean-square deviation of $0.18 \mathrm{~mL} / \mathrm{min} / \mathrm{g}$, as shown in Fig. 2e and Table 2, with corresponding Bland-Altman analysis shown in Fig. $2 \mathrm{f}$. Corresponding perfusion measurements in the LAD, LCx, and RCA individually are also shown in Table 2.

\section{Radiation dose}

For the reference standard technique, the total $\mathrm{CTDI}_{\mathrm{vol}}^{32}$ and SSDE were 184.00 and $298.58 \mathrm{mGy}$, respectively. For the low-dose cardiac CT technique, the total $\mathrm{CTDI}_{\mathrm{vol}}^{32}$ and SSDE were 8.05 and $12.80 \mathrm{mGy}$, respectively, where the $\mathrm{CTDI}_{\mathrm{vol}}^{32}$ and SSDE of rest perfusion alone combined with CTA were 5.75 and $9.14 \mathrm{mGy}$, stress perfusion alone were 2.30 and $3.66 \mathrm{mGy}$, and CTA alone were $4.6 \mathrm{mGy}$ and 7.31, respectively.

\section{Application}

For the three swine with LAD stenosis, nine low-dose cardiac CT acquisitions were performed: three per swine. Corresponding CFR versus stress perfusion measurements were then assessed in relation to previously reported physiological cutoff thresholds [9], and displayed as a coronary flow capacity map in Fig. 3, where the results show that noninvasive CFR and stress perfusion is in general agreement with invasive FFR. Low-dose CFR and stress perfusion maps with co-registered angiography $\left(\mathrm{V} 2_{\text {REST }}\right)$ in the absence and presence of a physiologically significant LAD stenosis $(\mathrm{FFR}=0.70)$ are also shown in Fig. 4

\section{Discussion}

\section{Indication of results}

Low-dose vessel-specific, rest perfusion, stress perfusion, and CFR measurement were in good agreement with corresponding reference standard measurement. Stress perfusion and CFR agreed with the physiological severity of induced LAD stenoses, i.e., stress perfusion and CFR decreased proportionally as FFR decreased, as expected with focal disease. The spatial distribution of CFR and stress perfusion also agreed with the induced flow conditions, where CFR and stress perfusion without a LAD stenosis remained high, while CFR and stress perfusion distal to a LAD stenosis with a FFR severity of 0.70 was markedly reduced. Furthermore, the total $\mathrm{CTDI}_{\mathrm{vol}}^{32}$ and SSDE of rest perfusion combined with CTA, stress perfusion, and CFR were only 8.05 and $12.80 \mathrm{mGy}$, respectively, corresponding to a maximum effective dose and size-specific effective dose of 1.8 and $2.87 \mathrm{mSv}$ for the low-dose cardiac CT technique, respectively, if using a standard chest conversion coefficient of $0.014 \mathrm{mSv} / \mathrm{mGy}$ and $16 \mathrm{~cm}$ of cranio-caudal coverage. By comparison, the total $\mathrm{CTDI}_{\mathrm{vol}}^{32}$ and SSDE of the reference standard technique were 184.00 and $298.58 \mathrm{mGy}$, corresponding to a maximum effective dose and size-specific effective dose of 41.22 and $66.88 \mathrm{mSv}$ to provide rest perfusion, CTA, stress perfusion, and CFR with the reference standard technique.

\section{Comparison to previous reports}

Stress dynamic CT perfusion has been shown to correlate well with invasive FFR [29]. However, due to methodological differences between techniques, various perfusion thresholds that lack agreement have been used to stratify CAD risk [5]. Consequently, CFR and CTA used in combination with stress perfusion have both been shown to improve the diagnostic sensitivity and specificity of CAD workup $[9,30]$. 
(a) Stress + Rest Perfusion Regression

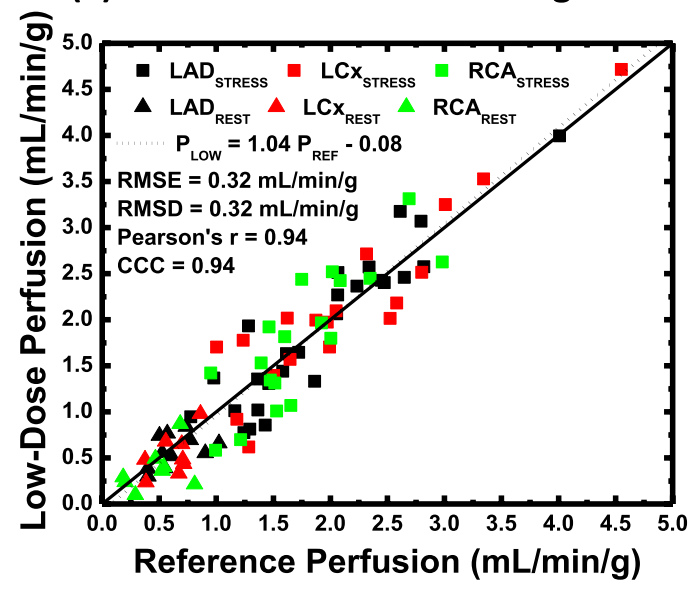

(c) Stress Perfusion Regression

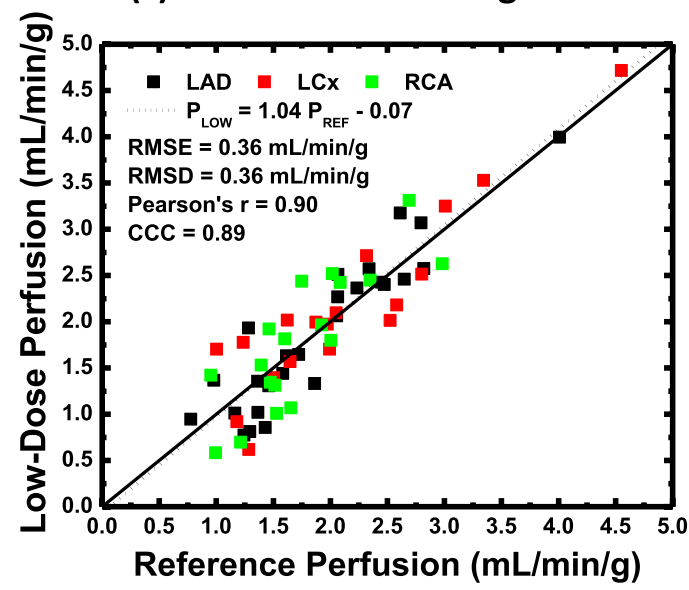

(e) Rest Perfusion Regression

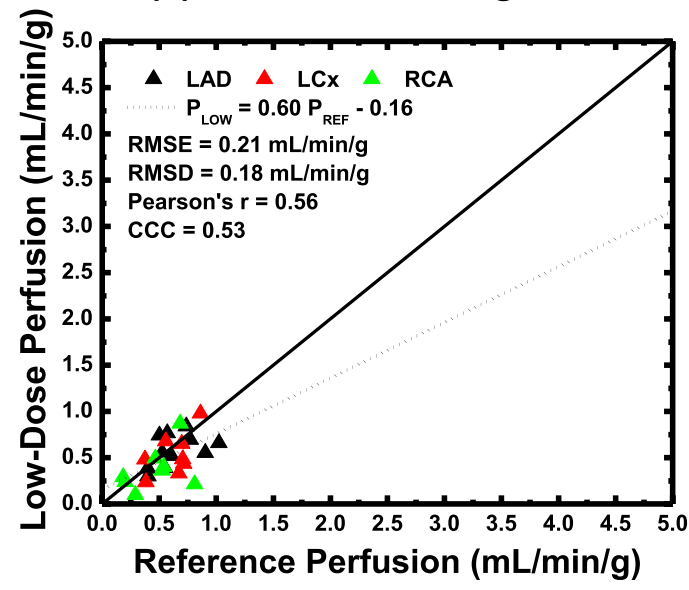

Fig. 2 Vessel-specific perfusion measurement analysis. a Low-dose vessel-specific stress and rest perfusion measurements $\left(\mathrm{P}_{\text {LOW }}\right)$ versus reference standard perfusion measurements $\left(\mathrm{P}_{\mathrm{REF}}\right)$ with $\mathbf{b}$ corresponding Bland-Altman analysis. c Low-dose vessel-specific stress only perfusion measurements $\left(\mathrm{P}_{\text {LOW }}\right)$ versus reference standard perfusion measurements $\left(\mathrm{P}_{\mathrm{REF}}\right)$ with $\mathbf{d}$ corresponding Bland-Altman analysis. e Low-dose vessel-specific rest only perfusion measurements $\left(\mathrm{P}_{\text {LOW }}\right)$ (b) Stress + Rest Perfusion Bland-Altman

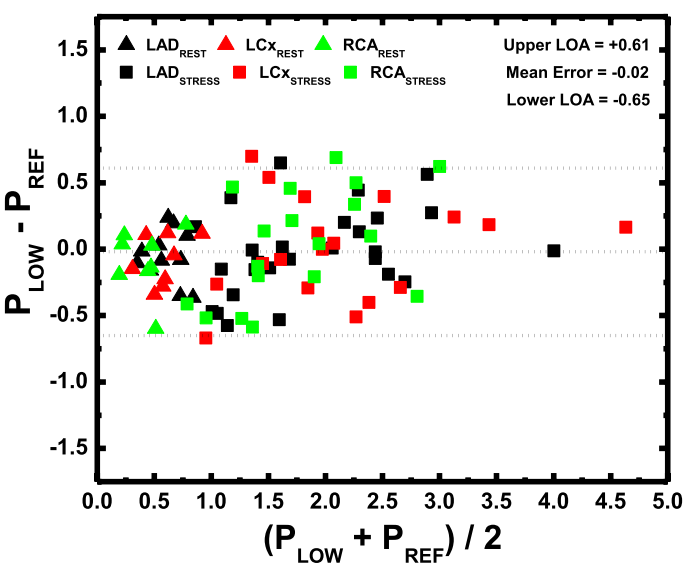

(d) Stress Perfusion Bland-Altman

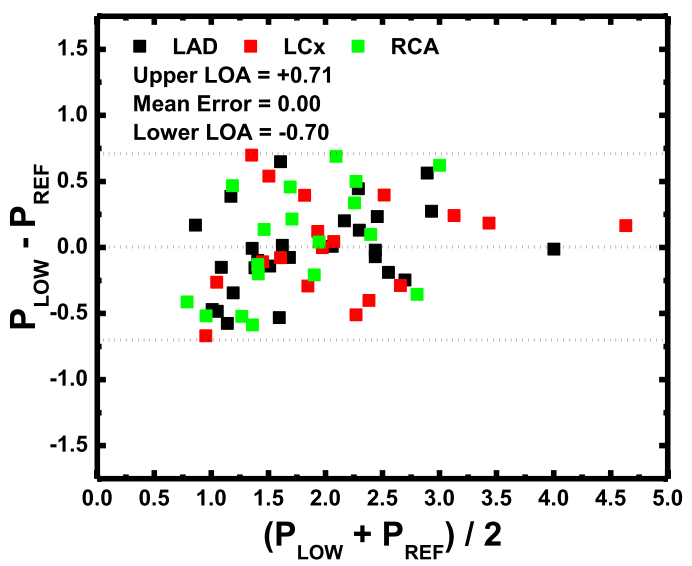

(f) Rest Perfusion Bland-Altman

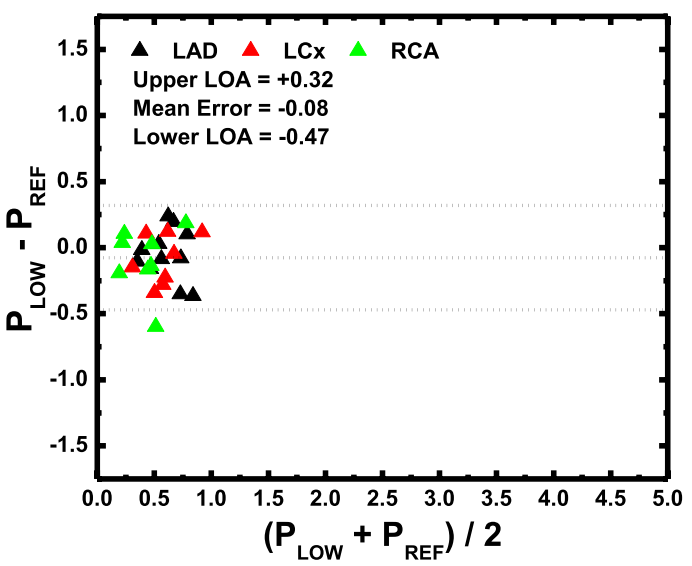

versus reference standard perfusion measurements $\left(\mathrm{P}_{\mathrm{REF}}\right)$ with $\mathbf{f}$ corresponding Bland-Altman analysis. LAD indicates left anterior descending coronary artery; LCx, left circumflex coronary artery; RCA, right coronary artery; RMSE, root-mean-square-error; RMSD, root-mean-square-deviation; CCC, Lin's concordance correlation; LOA, limits of agreement 
Table 2 Low-dose perfusion measurement and reference standard perfusion measurement accuracy and precision analysis

\begin{tabular}{|c|c|c|c|c|c|c|}
\hline Condition & Slope & Intercept & Pearson's r & Lin's CCC & $\begin{array}{l}\text { RMSE } \\
(\mathrm{mL} / \mathrm{min} / \mathrm{g})\end{array}$ & $\begin{array}{l}\text { RMSD } \\
(\mathrm{mL} / \mathrm{min} / \mathrm{g})\end{array}$ \\
\hline \multicolumn{7}{|c|}{$S T R E S S+R E S T$} \\
\hline LAD & $\begin{array}{l}1.04 \\
{[0.92,1.15]}\end{array}$ & $\begin{array}{l}-0.09 \\
{[-0.29,0.11]}\end{array}$ & $\begin{array}{l}0.95 \\
{[0.91,0.97]}\end{array}$ & $\begin{array}{l}0.95 \\
{[0.90,0.97]}\end{array}$ & 0.28 & 0.28 \\
\hline LCx & $\begin{array}{l}1.01 \\
{[0.87,1.16]}\end{array}$ & $\begin{array}{l}-0.05 \\
{[-0.33,0.22]}\end{array}$ & $\begin{array}{l}0.96 \\
{[0.90,0.98]}\end{array}$ & $\begin{array}{l}0.95 \\
{[0.90,0.98]}\end{array}$ & 0.32 & 0.32 \\
\hline RCA & $\begin{array}{l}1.09 \\
{[0.89,1.30]}\end{array}$ & $\begin{array}{l}-0.13 \\
{[-0.45,0.18]}\end{array}$ & $\begin{array}{l}0.92 \\
{[0.82,0.96]}\end{array}$ & $\begin{array}{l}0.90 \\
{[0.79,0.96]}\end{array}$ & 0.37 & 0.36 \\
\hline ALL & $\begin{array}{l}1.04 \\
{[0.96,1.12]}\end{array}$ & $\begin{array}{l}-0.08 \\
{[-0.22,0.05]}\end{array}$ & $\begin{array}{l}0.94 \\
{[0.92,0.96]}\end{array}$ & $\begin{array}{l}0.94 \\
{[0.91,0.96]}\end{array}$ & 0.32 & 0.32 \\
\hline \multicolumn{7}{|l|}{ STRESS } \\
\hline LAD & $\begin{array}{l}1.06 \\
{[0.88,1.25]}\end{array}$ & $\begin{array}{l}-0.14 \\
{[-0.51,0.23]}\end{array}$ & $\begin{array}{l}0.92 \\
{[0.84,0.97]}\end{array}$ & $\begin{array}{l}0.91 \\
{[0.82,0.96]}\end{array}$ & 0.31 & 0.31 \\
\hline LCx & $\begin{array}{l}0.98 \\
{[0.76,1.20]}\end{array}$ & $\begin{array}{l}0.04 \\
{[-0.47,0.55]}\end{array}$ & $\begin{array}{l}0.92 \\
{[0.80,0.97]}\end{array}$ & $\begin{array}{l}0.92 \\
{[0.79,0.97]}\end{array}$ & 0.36 & 0.36 \\
\hline RCA & $\begin{array}{l}1.13 \\
{[0.73,1.54]}\end{array}$ & $\begin{array}{l}-0.20 \\
{[-0.94,0.54]}\end{array}$ & $\begin{array}{l}0.83 \\
{[0.59,0.93]}\end{array}$ & $\begin{array}{l}0.79 \\
{[0.51,0.92]}\end{array}$ & 0.41 & 0.40 \\
\hline ALL & $\begin{array}{l}1.04 \\
{[0.91,1.16]}\end{array}$ & $\begin{array}{l}-0.07 \\
{[-0.33,0.19]}\end{array}$ & $\begin{array}{l}0.90 \\
{[0.85,0.94]}\end{array}$ & $\begin{array}{l}0.89 \\
{[0.83,0.94]}\end{array}$ & 0.36 & 0.36 \\
\hline \multicolumn{7}{|l|}{$R E S T$} \\
\hline LAD & $\begin{array}{l}0.41 \\
{[-0.17,0.99]}\end{array}$ & $\begin{array}{l}0.32 \\
{[-0.06,0.71]}\end{array}$ & $\begin{array}{l}0.47 \\
{[-0.18,0.83]}\end{array}$ & $\begin{array}{l}0.45 \\
{[-0.21,0.83]}\end{array}$ & 0.19 & 0.15 \\
\hline LCx & $\begin{array}{l}0.81 \\
{[-0.28,1.91]}\end{array}$ & $\begin{array}{l}0.03 \\
{[-0.67,0.73]}\end{array}$ & $\begin{array}{l}0.60 \\
{[-0.18,0.92]}\end{array}$ & $\begin{array}{l}0.52 \\
{[-0.29,0.90]}\end{array}$ & 0.20 & 0.17 \\
\hline RCA & $\begin{array}{l}0.46 \\
{[-0.48,1.39]}\end{array}$ & $\begin{array}{l}0.16 \\
{[-0.32,0.64]}\end{array}$ & $\begin{array}{l}0.44 \\
{[-0.39,0.87]}\end{array}$ & $\begin{array}{l}0.40 \\
{[-0.42,0.86]}\end{array}$ & 0.25 & 0.20 \\
\hline ALL & $\begin{array}{l}0.60 \\
{[0.24,0.97]}\end{array}$ & $\begin{array}{l}0.16 \\
{[-0.07,0.38]}\end{array}$ & $\begin{array}{l}0.56 \\
{[0.23,0.78]}\end{array}$ & $\begin{array}{l}0.53 \\
{[0.19,0.76]}\end{array}$ & 0.21 & 0.18 \\
\hline
\end{tabular}

Brackets indicate $95 \%$ confidence intervals

$L A D$ left anterior descending perfusion territory, $L C x$ left circumflex perfusion territory, $R C A$ right coronary artery perfusion territory, $A L L$ all coronary perfusion territories combined, Lin's $C C C$ Lin's concordance correlation coefficient, $R M S E$ root-mean-square error, $R M S D$ root-mean-square deviation
Still, despite efforts to lower tube voltage and tube current [31], as well as efforts to reduce the sampling frequency of dynamic CT perfusion [32], the cumulative radiation and contrast dose required to provide such stress perfusion, CFR, and CTA data all together is currently too high. In particular, the average dose of current CTA techniques is approximately $2.7 \mathrm{mSv}$ [33], while the average dose of current dynamic CT perfusion techniques is $>5 \mathrm{mSv}[5,14-16]$ owing to the number of volume scans necessary to provide stress perfusion metrics. Thus, by extension, if stress perfusion, CFR, and CTA data are acquired together with current techniques, the minimum effective dose quickly approaches $\sim 12.7 \mathrm{mSv}$, where the dose will be even higher if the cranio-caudal coverage of perfusion scanning is increased to encompass the whole heart. While such a dose remains low as compared to the reference standard technique of this study, the reference technique employed 40 high-tube-current volumes scans with $16 \mathrm{~cm}$ of cranio-caudal coverage for the purpose of validation alone; hence, it would not be used clinically.
Nevertheless, other groups are pursuing alternative approaches to comprehensive CT-based cardiovascular diagnostics. Lubbers et al. used a tiered approach, where patients with positive calcium scores underwent CTA, those with positive CTAs underwent CT perfusion testing, and those with significant perfusion defects underwent invasive catheterization. Such a testing strategy improved the accuracy of CAD diagnosis as compared to standard testing, reduced the rate of negative catheterization, and exposed patients with lower risk, i.e. negative calcium scores or negative CTA, to less radiation and contrast dose. Nevertheless, the mean radiation doses were 1.3, 3.5, and $10.6 \mathrm{mSv}$ for calcium scoring, CTA, and stress CT perfusion, yielding a total mean radiation dose of $15.5 \mathrm{mSv}$ for patients receiving all three tests [34]. Alternatively, Pontone et al. proposed a protocol comprised of CTA followed by static stress CT perfusion, where FFR-CT was also derived from the CTA data. While the results showed improved diagnostic accuracy when incorporating FFR-CT and stress $\mathrm{CT}$ perfusion, again the mean radiation dose of 
Fig. 3 Coronary flow capacity map in the presence of LAD stenoses. Vessel-specific CFR versus stress perfusion in the absence of stenoses, as well as in the presence of LAD stenoses with fractional flow reserve (FFR) severities of $0.90-0.70$ are shown. LAD indicates left anterior descending perfusion territory; LCX, left circumflex territory; RCA, right coronary artery territory. Graphical Color Scheme: Red = Normal CFR and/or stress perfusion, Orange $=$ No ischemia but minimally reduced CFR and/or stress perfusion; Yellow $=$ No ischemia but mildly reduced CFR and/or stress perfusion; Green $=$ moderately reduced CFR and/or stress perfusion; Blue $=$ definite ischemia and/or myocardial steal; Black $=$ predominantly scar [9]

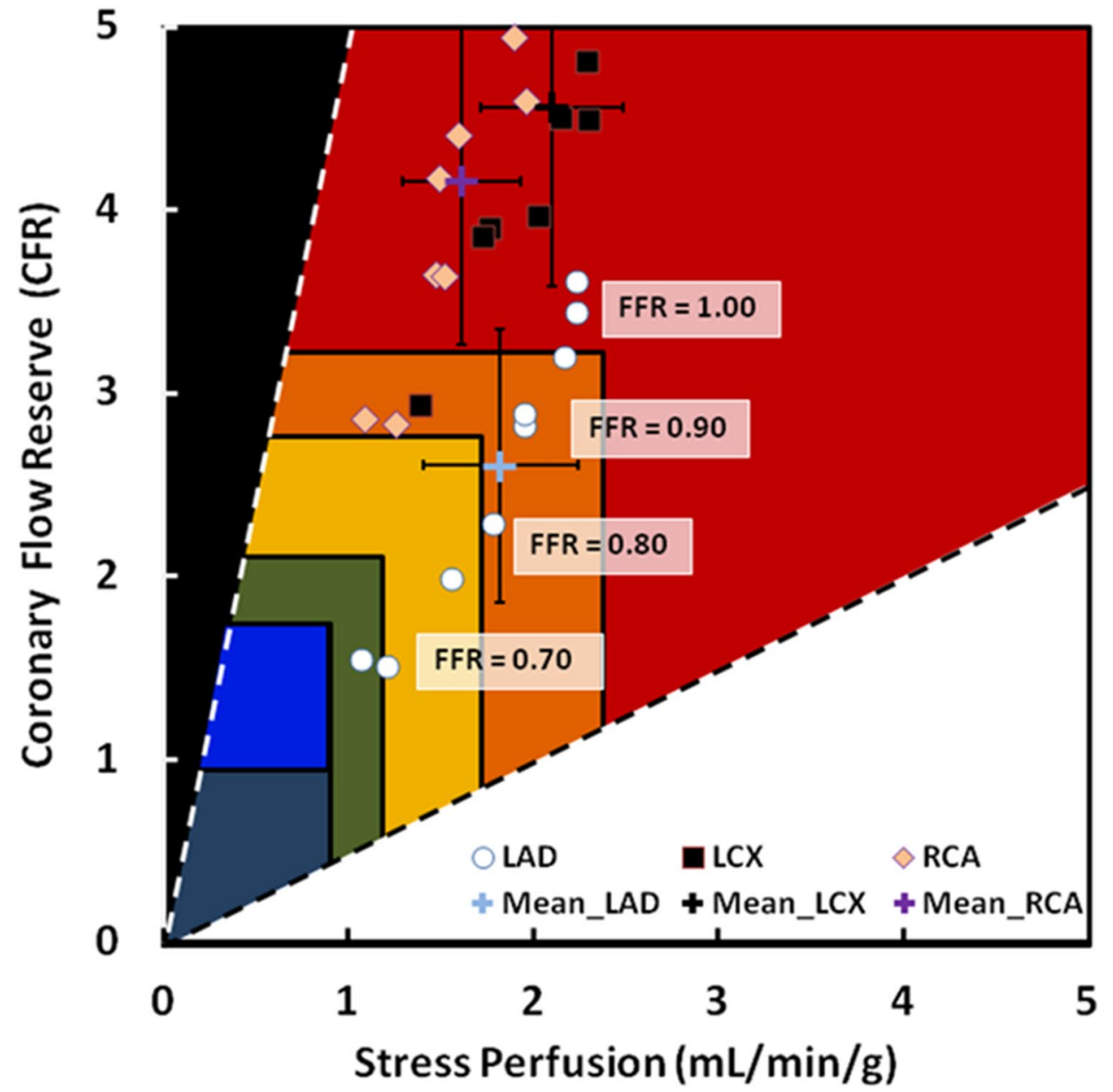

CTA and static stress perfusion combined was $5.2 \mathrm{mSv}$ [16], without providing absolute perfusion in $\mathrm{mL} / \mathrm{min} / \mathrm{g}$. Fortunately, our low-dose CT technique provides a new method to combine CTA, rest and stress perfusion, as well as CFR on a vessel-specific basis at a fraction of the radiation dose. Moreover, there is potential to implement our technique as a tiered approach, i.e., CTA and rest perfusion first followed by stress perfusion in patients with positive CTAs, for additional dose savings.

\section{Implications and practical applications of the present study}

The low-dose cardiac CT technique was shown to enable accurate, vessel-specific rest perfusion, stress perfusion, and CFR measurement, with simultaneously acquired coregistered CTA data using only four volume scans and two contrast injections, respectively, where such a protocol had not been fully realized by our prior work [18-21]. Hence, the present work is valuable as it fully demonstrates the potential for substantial radiation and contrast dose reduction in comprehensive CT-based assessment of
CAD. Likewise, the protocol provides voxel-by-voxel and vessel specific [18] stress perfusion and CFR measurements, where such flow capacity mapping combined with CTA may further improve the accuracy of CAD localization, assessment, and intervention, especially since such metrics are highly predictive of cardiac mortality [3, 9]. Specifically, for focal stenosis with large contiguous regions of myocardium demonstrating ischemic coronary flow capacity, revascularization would be indicated. Alternatively, for focal stenosis with small or distal regions of ischemic coronary flow capacity, as well as for globally reduced flow capacity in the absence of stenosis, i.e., diffuse versus microvascular disease, optimal medical therapy would be indicated. Finally, if the V2 ${ }_{\text {STRESS }}$ exposure time is increased, there is also potential for cardiac output, ejection fraction, wall motion, and myocardial strain to be assessed [35] by our technique. Hence, if employed clinically, the low-dose cardiac CT technique could be used in place of stress echocardiography, CTA, and nuclear imaging as a "one-stop-shop" CT-based approach for low-dose morphological and physiological assessment of CAD. Particularly, the technique could be used in both inpatient 
Fig. 4 Example visualization of the low-dose cardiac CT technique. Low-dose CFR and stress perfusion in the absence and presence of a significant left anterior descending (LAD) coronary artery balloon stenosis $(\mathrm{FFR}=0.70)$, with co-registered CTA displayed. A LAD perfusion deficit is shown (red arrows). The color bars indicate low-dose CFR and stress perfusion measurement in $\mathrm{mL} / \mathrm{min} / \mathrm{g}$

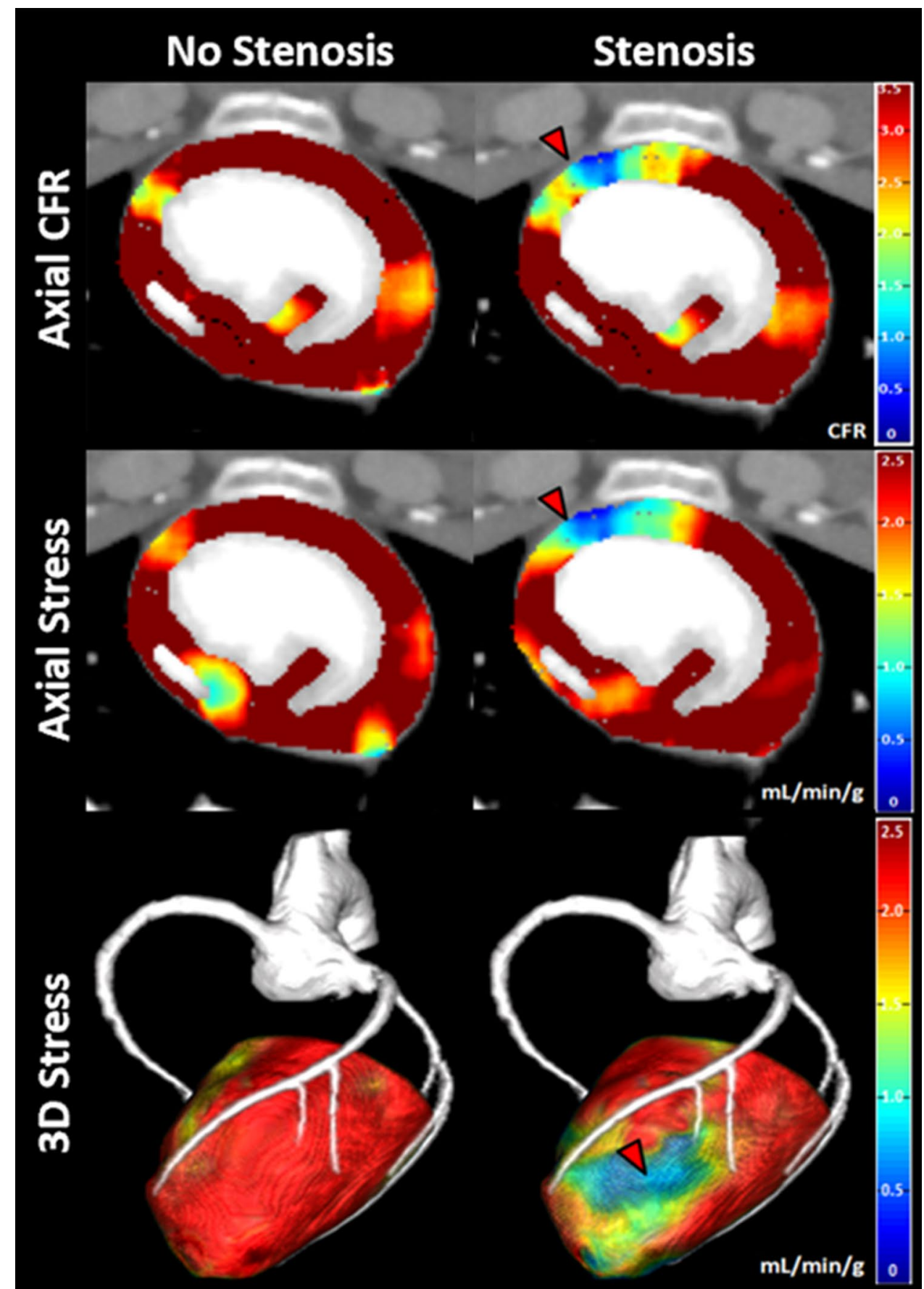

and outpatient settings to assess risk and determine management of asymptomatic and symptomatic patients with stable or unstable angina. Additionally, pre- and posttreatment response data could be assessed to determine the efficacy of coronary stenting, coronary artery bypass grafting, and optimal medical therapy. Overall, the goal of the low-dose cardiac CT technique will be to reduce the rates of major adverse cardiac events in patients with CAD by improving risk assessment and optimizing downstream intervention.

\section{Limitations}

While the time between paired acquisitions was 15 -min, given that repeat injections were made in each animal, small increases in the baseline blood pool enhancement over time were unavoidable. However, the use of prospective triggering at $140 \mathrm{HU}$ above the baseline blood pool enhancement maintained accurate timing and perfusion measurement. The variable time delays between V1 and V2 for the low-dose acquisitions were also estimated from the reference standard 
acquisitions, which is clinically unrealistic. Consequently, each time delay can be determined with a diluted test bolus and single slice CINE scanning [36], with only slight increases in contrast and radiation dose. The proper time delay may also be estimated as a function of the contrast injection time plus a fixed dispersion time [37], where the accuracy of perfusion measurement is maintained as long as the V2 volume scan is acquired within approximately \pm 2 cardiac cycles of the true peak of the aortic enhancement [37]. Nevertheless, true prospective acquisition of V1 and V2 using such timing remains to be assessed. Hence, future work should implement these timing approaches, while also evaluating the impact of contrast injection volume, rate, and sub-optimal acquisition timing on measurement accuracy, especially in the presence of cardiac pathology.

The swine also had a small effective diameter $(23 \mathrm{~cm})$ as compared to the average $34 \mathrm{~cm}$ effective diameter of patients with CAD [38], i.e., the performance of the technique may degrade in larger patients due to increased photon starvation and attenuation bias [39]. However, exposure control methods can maintain a fixed measurement noise for larger effective diameters, although effective dose increases proportionally, as previously approximated with water phantoms [21]. Hence, a patient with an average effective diameter of $34 \mathrm{~cm}$ [38] would theoretically receive a maximum effective dose of approximately 3.90 or $5.20 \mathrm{mSv}$, for combined rest perfusion, stress perfusion, CFR, and CTA using 12 or $16 \mathrm{~cm}$ [38] of craniocaudal coverage, respectively; still much lower than what is possible with current CTA and CT perfusion techniques.

On average, the swine also had high heart rates. To avoid blunting of stress perfusion, beta-blockers were not given. Nitroglycerin was also avoided during CTA to prevent further exacerbations in heart rate. As a result, the images were motion degraded. That said, the low-dose technique derives perfusion using the integrated change in $\mathrm{HU}$ within the entire myocardium over time; thus, the impact of motion on the accuracy of perfusion measurement was not significant. Still, despite optimal CTA acquisition at the peak of the aortic enhancement [36,37], the impact of motion combined with metal artifacts from the angioplasty balloons and wires significantly reduced coronary image quality, preventing morphological cross-sectional assessment of the stenoses. However, such motion and metal artifacts were not significant enough to prevent coronary centerline extraction; hence, the accuracy of minimum-cost-path myocardial assignment was unaffected. Factors that impact the accuracy of assignment, i.e., the accuracy of centerline extraction, include poor coronary enhancement, severe motion, and premature coronary truncation such as that caused by total occlusion. Hence, future work should also aim to address the challenges of poor enhancement, severe coronary calcification, arrythmias, high heart rates, and occlusive disease on both
CTA quality and minimum-cost-path myocardial assignment. As an alternate solution in this study, invasive FFR was employed as a functional metric of stenosis severity. Yet, the number of animals with balloon stenoses remained limited, especially as compared to prior work, where the relationship between perfusion and invasive FFR was thoroughly described [20]. Hence, additional prospective work in more animals with stenosis remains necessary.

Lastly, only segmental disease was assessed in the absence of infarct, i.e., multi-vessel disease, diffuse disease, microvascular disease, and myocardial scar were not evaluated. However, the technique can spatially resolve both absolute perfusion (in $\mathrm{mL} / \mathrm{min} / \mathrm{g}$ ) and CFR on a voxel-by-voxel and vessel-specific basis, where such metrics overcome the normalization dependent limitations of static perfusion. Hence, detection of focal, gradient, and global perfusion deficits, as well as balanced ischemia and myocardial scar are still feasible. Nonetheless, the accuracy of voxel-by-voxel perfusion and CFR measurement depends on image noise. Fortunately, voxel binning can be used to suppress image noise while maintaining adequate spatial resolution. More importantly, minimum-cost-path myocardial assignment $[18,28]$ can be used to generate entire coronary perfusion territories or sub-territories, even in the presence of multifocal CAD, assuming distal centerlines can be extracted. Hence, vessel-specific perfusion and CFR measurements are possible, while suppressing measurement variance [19, 20]. Finally, extrapolation of other perfusion parameters, such as perfusion blood volume, were not assessed and should be the subject of future work.

\section{Conclusion}

The low-dose cardiac CT technique is a new method that enables accurate, vessel-specific rest perfusion, stress perfusion, and CFR measurement, with simultaneously acquired CTA data, using only four volume scans and two contrast injections, respectively. As a result, the total combined radiation dose of CT-based CAD workup has the potential to be reduced.

Acknowledgements This work was supported, in part, by the Department of Radiological Sciences at the University of California, Irvine, by the American Heart Association under Award No. 17CPRE33650059, and by the National Heart Lung and Blood Institute of the National Institutes of Health under Award No. 1F30HL13728801A1.

Author contributions All data was acquired by all the authors. All data was then analyzed by authors LH and ShM. The manuscript was then drafted by $\mathrm{LH}$ and was revised by all the authors.

Funding This work was supported, in part, by the Department of Radiological Sciences at the University of California, Irvine, by the American Heart Association under award number 17CPRE33650059, 
and by the National Heart Lung and Blood Institute of the National Institutes of Health under award number 1F30HL13728801A1.

\section{Compliance with ethical standards}

Conflict of interest The authors do not have any conflicts-of-interest or competing interests to disclose.

Open Access This article is licensed under a Creative Commons Attribution 4.0 International License, which permits use, sharing, adaptation, distribution and reproduction in any medium or format, as long as you give appropriate credit to the original author(s) and the source, provide a link to the Creative Commons licence, and indicate if changes were made. The images or other third party material in this article are included in the article's Creative Commons licence, unless indicated otherwise in a credit line to the material. If material is not included in the article's Creative Commons licence and your intended use is not permitted by statutory regulation or exceeds the permitted use, you will need to obtain permission directly from the copyright holder. To view a copy of this licence, visit http://creativecommons.org/licenses/by/4.0/.

\section{References}

1. De Bruyne B, Pijls NHJ, Kalesan B, Barbato E, Tonino PAL, Piroth Z, Jagic N, Möbius-Winkler S, Rioufol G, Witt N, Kala P, MacCarthy P, Engström T, Oldroyd KG, Mavromatis K, Manoharan G, Verlee P, Frobert O, Curzen N, Johnson JB, Jüni P, Fearon WF (2012) Fractional flow reserve-guided PCI versus medical therapy in stable coronary disease. N Engl J Med 367(11):991-1001. https://doi.org/10.1056/NEJMoa1205361

2. Chen MY, Rochitte CE, Arbab-Zadeh A, Dewey M, George RT, Miller JM, Niinuma H, Yoshioka K, Kitagawa K, Sakuma H, Laham R, Vavere AL, Cerci RJ, Mehra VC, Nomura C, Kofoed KF, Jinzaki M, Kuribayashi S, Scholte AJ, Laule M, Tan SY, Hoe J, Paul N, Rybicki FJ, Brinker JA, Arai AE, Matheson MB, Cox C, Clouse ME, Di Carli MF, Lima JAC (2017) Prognostic value of combined CT angiography and myocardial perfusion imaging versus invasive coronary angiography and nuclear stress perfusion imaging in the prediction of major adverse cardiovascular events: the CORE320 multicenter study. Radiology 284(1):55-65. https ://doi.org/10.1148/radiol.2017161565

3. Murthy VL, Naya M, Foster CR, Hainer J, Gaber M, Di Carli G, Blankstein R, Dorbala S, Sitek A, Pencina MJ, Di Carli MF (2011) Improved cardiac risk assessment with noninvasive measures of coronary flow reserve. Circulation 124(20):2215-2224. https:// doi.org/10.1161/circulationaha.111.050427

4. Jablonowski R, Wilson MW, Do L, Hetts SW, Saeed M (2015) Multidetector CT measurement of myocardial extracellular volume in acute patchy and contiguous infarction: validation with microscopic measurement. Radiology 274(2):370-378. https:// doi.org/10.1148/radiol.14140131

5. Danad I, Szymonifka J, Schulman-Marcus J, Min JK (2016) Static and dynamic assessment of myocardial perfusion by computed tomography. Eur Heart J 17(8):836-844. https://doi.org/10.1093/ ehjci/jew044

6. Rieber J, Huber A, Erhard I, Mueller S, Schweyer M, Koenig A, Schiele TM, Theisen K, Siebert U, Schoenberg SO, Reiser M, Klauss V (2006) Cardiac magnetic resonance perfusion imaging for the functional assessment of coronary artery disease: a comparison with coronary angiography and fractional flow reserve. Eur Heart J 27(12):1465-1471. https://doi.org/10.1093/eurheartj/ ehl039
7. Doukky R, Hayes K, Frogge N, Balakrishnan G, Dontaraju VS, Rangel MO, Golzar Y, Garcia-Sayan E, Hendel RC (2013) Impact of appropriate use on the prognostic value of single-photon emission computed tomography myocardial perfusion imaging. Circulation 128(15):1634-1643. https://doi.org/10.1161/circulatio naha. 113.002744

8. Ziadi MC, Dekemp RA, Williams KA, Guo A, Chow BJ, Renaud JM, Ruddy TD, Sarveswaran N, Tee RE, Beanlands RS (2011) Impaired myocardial flow reserve on rubidium- 82 positron emission tomography imaging predicts adverse outcomes in patients assessed for myocardial ischemia. J Am Coll Cardiol 58(7):740 748. https://doi.org/10.1016/j.jacc.2011.01.065

9. Johnson NP, Gould KL (2012) Integrating noninvasive absolute flow, coronary flow reserve, and ischemic thresholds into a comprehensive map of physiological severity. JACC Cardiovasc Imaging 5(4):430-440. https://doi.org/10.1016/j.jcmg.2011.12.014

10. Saeed M, Hetts SW, Do L, Wilson MW (2013) Assessment of microembolization associated with revascularization in acute myocardial infarction: MDCT cardiac perfusion and function study. Int J Cardiovasc Imaging 29(8):1861-1869. https://doi. org/10.1007/s10554-013-0273-z

11. Bindschadler M, Modgil D, Branch KR, La Riviere PJ, Alessio AM (2014) Comparison of blood flow models and acquisitions for quantitative myocardial perfusion estimation from dynamic CT. Phys Med Biol 59(7):1533-1556. https://doi. org/10.1088/0031-9155/59/7/1533

12. Ishida M, Kitagawa $K$, Ichihara $T$, Natsume $T$, Nakayama R, Nagasawa N, Kubooka M, Ito T, Uno M, Goto Y, Nagata M, Sakuma H (2016) Underestimation of myocardial blood flow by dynamic perfusion CT: explanations by two-compartment model analysis and limited temporal sampling of dynamic CT. J Cardiovasc Comput Tomogr 10(3):207-214. https://doi. org/10.1016/j.jcct.2016.01.008

13. van Assen M, Pelgrim GJ, Slager E, van Tuijl S, Schoepf UJ, Vliegenthart R, Oudkerk M (2019) Low CT temporal sampling rates result in a substantial underestimation of myocardial blood flow measurements. Int J Cardiovasc Imaging 35(3):539-547. https://doi.org/10.1007/s10554-018-1451-9

14. Ho KT, Chua KC, Klotz E, Panknin C (2010) Stress and rest dynamic myocardial perfusion imaging by evaluation of complete time-attenuation curves with dual-source CT. JACC Cardiovasc Imaging 3(8):811-820. https://doi.org/10.1016/j. jcmg.2010.05.009

15. Rossi A, Merkus D, Klotz E, Mollet N, de Feyter PJ, Krestin GP (2014) Stress myocardial perfusion: imaging with multidetector CT. Radiology 270(1):25-46. https://doi.org/10.1148/radio 1.13112739

16. Pontone G, Baggiano A, Andreini D, Guaricci AI, Guglielmo M, Muscogiuri G, Fusini L, Soldi M, Del Torto A, Mushtaq S, Conte E, Calligaris G, De Martini S, Ferrari C, Galli S, Grancini L, Olivares P, Ravagnani P, Teruzzi G, Trabattoni D, Fabbiocchi F, Montorsi P, Rabbat MG, Bartorelli AL, Pepi M (2019) Dynamic stress computed tomography perfusion with a whole-heart coverage scanner in addition to coronary computed tomography angiography and fractional flow reserve computed tomography derived. JACC Cardiovasc Imaging 12(12):2460-2471

17. Ziemer BP, Hubbard L, Lipinski J, Molloi S (2015) Dynamic $\mathrm{CT}$ perfusion measurement in a cardiac phantom. Int J Cardiovasc Imaging 31(7):1451-1459. https://doi.org/10.1007/s 1055 4-015-0700-4

18. Malkasian S, Hubbard L, Dertli B, Kwon J, Molloi S (2018) Quantification of vessel-specific coronary perfusion territories using minimum-cost path assignment and computed tomography angiography: validation in a swine model. J Cardiovasc Comput Tomogr 12(5):425-435 
19. Hubbard L, Lipinski J, Ziemer B, Malkasian S, Sadeghi B, Javan H, Groves EM, Dertli B, Molloi S (2018) Comprehensive assessment of coronary artery disease by using first-pass analysis dynamic CT perfusion: validation in a swine model. Radiology 286(1):93-102. https://doi.org/10.1148/radiol.2017162821

20. Hubbard L, Ziemer B, Lipinski J, Sadeghi B, Javan H, Groves EM, Malkasian S, Molloi S (2016) Functional assessment of coronary artery disease using whole-heart dynamic computed tomographic perfusion. Circ Cardiovasc Imaging 9(12):1-8. https:// doi.org/10.1161/circimaging.116.005325

21. Hubbard L, Malkasian S, Zhao Y, Abbona P, Kwon J, Molloi S (2019) Low-radiation-dose stress myocardial perfusion measurement using first-pass analysis dynamic computed tomography: a preliminary investigation in a swine model. Invest Radiol 54(12):774-780. https://doi.org/10.1097/rli.0000000000000613

22. Masshoff W, Scheidt D, Reimers HF (1967) Quantitative determination of adipose and myocardial tissue in cadaver hearts. Virchows Arch Pathol Anat Physiol Klin Med 342(2):184-189

23. Boone J, Strauss K, Cody D, McCollough C, McNitt-Gray M, Toth T, Goske M, Frush D (2011) Size-specific dose estimates (SSDE) in pediatric and adult body CT examinations: report of AAPM task group 204. American Association of Physicists in Medicine, College Park

24. Yamada Y, Jinzaki M, Hosokawa T, Tanami Y, Sugiura H, Abe T, Kuribayashi S (2012) Dose reduction in chest CT: comparison of the adaptive iterative dose reduction $3 \mathrm{D}$, adaptive iterative dose reduction, and filtered back projection reconstruction techniques. Eur J Radiol 81(12):4185-4195. https://doi.org/10.1016/j.ejrad .2012.07.013

25. Modat M, Ridgway GR, Taylor ZA, Lehmann M, Barnes J, Hawkes DJ, Fox NC, Ourselin S (2010) Fast free-form deformation using graphics processing units. Comput Methods Programs Biomed 98(3):278-284. https://doi.org/10.1016/j. cmpb.2009.09.002

26. de Jonge GJ, van Ooijen PMA, Overbosch J, Gueorguieva AL, Janssen-van der Weide MC, Oudkerk M (2011) Comparison of (semi-)automatic and manually adjusted measurements of left ventricular function in dual source computed tomography using three different software tools. Int J Cardiovasc Imaging 27(6):787-794. https://doi.org/10.1007/s10554-010-9727-8

27. Dewey M, Schnapauff D, Laule M, Lembcke A, Borges AC, Rutsch W, Hamm B, Rogalla P (2004) Multislice CT coronary angiography: evaluation of an automatic vessel detection tool. Rofo 176(4):478-483. https://doi.org/10.1055/s-2004-812991

28. Malkasian S, Hubbard L, Abbona P, Dertli B, Kwon J, Molloi S (2020) Vessel-specific coronary perfusion territories using a CT angiogram with a minimum cost path technique and its direct comparison to the American Heart Association 17-segment model. Eur Radiol 30(6):3334-3345. https://doi.org/10.1007/ s00330-020-06697-w

29. Rossi A, Papadopoulou SL, Pugliese F, Russo B, Dharampal AS, Dedic A, Kitslaar PH, Broersen A, Meijboom WB, van Geuns RJ, Wragg A, Ligthart J, Schultz C, Petersen SE, Nieman K, Krestin GP, de Feyter PJ (2014) Quantitative computed tomographic coronary angiography: does it predict functionally significant coronary stenoses? Circ Cardiovasc Imaging 7(1):43-51. https:// doi.org/10.1161/circimaging.112.000277

30. George RT, Mehra VC, Chen MY, Kitagawa K, Arbab-Zadeh A, Miller JM, Matheson MB, Vavere AL, Kofoed KF, Rochitte CE, Dewey M, Yaw TS, Niinuma H, Brenner W, Cox C, Clouse ME, Lima JA, Di Carli M (2014) Myocardial CT perfusion imaging and SPECT for the diagnosis of coronary artery disease: a head-to-head comparison from the CORE320 multicenter diagnostic performance study. Radiology 272(2):407-416. https://doi. org/10.1148/radiol.14140806

31. Kim SM, Cho YK, Choe YH (2014) Adenosine-stress dynamic myocardial perfusion imaging using 128-slice dual-source CT in patients with normal body mass indices: effect of tube voltage, tube current, and iodine concentration on image quality and radiation dose. Int J Cardiovasc Imaging 30(Suppl 2):95-103. https:// doi.org/10.1007/s10554-014-0524-7

32. Yokoi T, Tanabe Y, Kido T, Kurata A, Kido T, Uetani T, Ikeda S, Izutani H, Miyagawa M, Mochizuki T (2019) Impact of the sampling rate of dynamic myocardial computed tomography perfusion on the quantitative assessment of myocardial blood flow. Clin Imaging 56:93-101. https://doi.org/10.1016/j.clini mag.2019.03.016

33. Stocker TJ, Deseive S, Leipsic J, Hadamitzky M, Chen MY, Rubinshtein R, Heckner M, Bax JJ, Fang XM, Grove EL, Lesser J, Maurovich-Horvat P, Otton J, Shin S, Pontone G, Marques H, Chow B, Nomura CH, Tabbalat R, Schmermund A, Kang JW, Naoum C, Atkins M, Martuscelli E, Massberg S, Hausleiter J (2018) Reduction in radiation exposure in cardiovascular computed tomography imaging: results from the PROspective multicenter registry on radiaTion dose Estimates of cardiac CT angIOgraphy iN daily practice in 2017 (PROTECTION VI). Eur Heart J 39(41):3715-3723. https://doi.org/10.1093/eurheartj/ehy546

34. Lubbers M, Coenen A, Kofflard M, Bruning T, Kietselaer B, Galema T, Kock M, Niezen A, Das M, van Gent M, van den Bos E-J, van Woerkens L, Musters P, Kooij S, Nous F, Budde R, Hunink M, Nieman K (2018) Comprehensive cardiac CT with myocardial perfusion imaging versus functional testing in suspected coronary artery disease: the multicenter randomized CRESCENT-II trial. JACC Cardiovasc Imaging 11(11):16251636. https://doi.org/10.1016/j.jcmg.2017.10.010

35. Pourmorteza A, Schuleri KH, Herzka DA, Lardo AC, McVeigh ER (2012) A new method for cardiac computed tomography regional function assessment: stretch quantifier for endocardial engraved zones (SQUEEZ). Circ Cardiovasc Imaging 5(2):243250. https://doi.org/10.1161/circimaging.111.970061

36. Hubbard L, Malkasian S, Zhao Y, Abbona P, Molloi S (2018) Contrast-to-noise ratio optimization in coronary computed tomography angiography: validation in a swine model. Acad Radiol 25:e115-e125

37. Hubbard L, Malkasian S, Zhao Y, Abbona P, Molloi S (2019) Timing optimization of low-dose first-pass analysis dynamic CT myocardial perfusion measurment: validation in a swine model. Eur Radiol Exp 3(16):1-9

38. Chen MY, Shanbhag SM, Arai AE (2013) Submillisievert median radiation dose for coronary angiography with a second-generation 320-detector row CT scanner in 107 consecutive patients. Radiology 267(1):76-85. https://doi.org/10.1148/radiol.13122621

39. Mirsadraee S, Weir NW, Connolly S, Murchison JT, Reid JH, Hirani N, Connell M, van Beek EJ (2015) Feasibility of radiation dose reduction using AIDR-3D in dynamic pulmonary CT perfusion. Clin Radiol 70(8):844-851. https://doi.org/10.1016/j. crad.2015.04.004

Publisher's Note Springer Nature remains neutral with regard to jurisdictional claims in published maps and institutional affiliations. 